\title{
Comunicação
}

[Communication]

\section{Concordância entre duas técnicas coproparasitológicas para diagnóstico de Fasciola hepatica em bovinos}

\author{
[Evaluation of two available methods to detect eggs of Fasciola hepatica in cattle faeces] \\ R.N. Faria ${ }^{1}$, M.C. Cury ${ }^{2 *}$, W.S. Lima ${ }^{3}$ \\ ${ }^{1}$ Instituto Mineiro de Agropecuária de Minas Gerais - Belo Horizonte, MG \\ ${ }^{2}$ Instituto de Ciências Biomédicas - UFU \\ Av. Pará 1720 - Campus Umuarama \\ 38400-902 - Uberlândia, MG \\ ${ }^{3}$ Instituto de Ciências Biológicas - UFMG - Belo Horizonte, MG
}

Entre as infestações por helmintos que acometem os bovinos, a ocasionada pelo trematódeo Fasciola hepatica é uma das mais preocupantes, por causar perdas econômicas, devido à diminuição da produção de leite e carne, condenação de fígados parasitados, abortos, aumento da taxa de mortalidade e gastos excessivos com o controle (Oakley et al., 1979).

A fasciolose apresenta distribuição cosmopolita e a presença do parasito é confirmada, usualmente, pela detecção de ovos nas fezes (Anderson et al., 1999). Novos métodos de diagnóstico, como o ELISA de captura, com o uso de coproantígeno, estão sendo utilizados. Estes testes são mais sensíveis que os métodos coprológicos, porém falham na detecção de formas imaturas ativas e não informam o número de ovos ou a proporção de hospedeiros definitivos que disseminam ovos no meio ambiente (Duménigo et al., 2000).

De acordo com Boray (1969), os métodos de sedimentação são os mais sensíveis no diagnóstico coproparasitológico de fascilose. Outros métodos que utilizam formalina e éter, como solvente, e a centrifugação para concentração de ovos são adaptados e empregados (Shore e Ash, 1973; Grock et al., 1998). Das técnicas mais conhecidas destacam-se as de Watanabe et al. (1953), de Dennis et al. (1954), de Girão (1982), a de filtro de Visser e a de filtração seqüencial em dois tamises metálicos em aparelho de Flukefinder ${ }^{R}$.

O objetivo deste trabalho é avaliar o grau de concordância entre as técnicas de quatro tamises e de filtração seqüencial, realizadas em fezes de bovinos.

Amostras de fezes de 1076 bovinos foram coletadas em 71 diferentes propriedades rurais, sorteadas aleatoriamente, do município de Itajubá-MG, foram colhidas, de quatro em quatro semanas, totalizando 2005 amostras.

Com o auxílio de sacos plásticos etiquetados com a identificação do animal e da fazenda, as amostras foram coletadas diretamente da ampola retal dos bovinos. Foi estabelecido que fossem coletadas as fezes de até 20 bovinos, preferencialmente aqueles com idade acima de 12 meses, independente de raça e sexo. Nas propriedades onde o número era inferior ao estabelecido, foram coletadas fezes de todos os animais.

As amostras identificadas foram acondicionadas em caixa de isopor com gelo e transportadas ao laboratório. Foram pesados dois gramas de fezes para serem submetidos à técnica de quatro tamises metálicos (T4) modificado por Girão e Ueno (1985) e quatro gramas para a utilização na

Recebido em 24 de outubro de 2007

Aceito em 27 de abril de 2008

Autor para correspondência (corresponding author)

E-mail: cury@umuarama.ufu.br 
técnica de processamento pela filtração seqüencial em dois tamises pelo aparelho de Flukefinder ${ }^{\circledR}(\mathrm{FF})$. Esse aparelho é constituído de dois tamises, dispostos um sobre o outro com malhas de 180 e 250 polegadas (aberturas de 96 a $65 \mathrm{~mm}$, respectivamente).

A análise dos resultados dos exames coproparasitológicos empregados, foram realizadas pelo programa estatístico winEpiscope 1.0 , e para determinar a proporção da concordância, fora o acaso, utilizou-se a escala de concordância do índice Kappa proposto por Andrade e Zicker (1977).

Setecentos e setenta e seis amostras apresentaram-se positivas e 1108 negativas para as duas técnicas; 60 revelaram-se positivas somente para T4 e 61 apresentaram positividade apenas para $\mathrm{FF}$.

Utilizando-se nível de confiança de 95\%, observaram-se uma proporção de confiança de 0,940, uma proporção de concordância esperada de 0,514, uma concordância máxima possível, fora o acaso, de 0,486 e índice Kappa de 0,876. De acordo com a escala de concordância do Kappa, proposto por Andrade e Zicker (1977), os valores encontrados, entre 0,81 e 0,99 , foram classificados como ótimos.

Nos resultados da avaliação de concordância, considerando nível de confiança de 95\%, obtiveram-se $92,7 \%$ de sensibilidade, $94,9 \%$ de especificidade, $92,8 \%$ de valor preditivo positivo (VPP) e $94,8 \%$ de valor preditivo negativo (VPN).

A eficiência de várias técnicas de diagnóstico utilizadas para a fasciolose, foi estudada por Girão e Ueno (1985), Abidu et al. (1996), Anderson et al. (1999), Conceição et al. (2002) e Kleiman et al. (2005).
Neste estudo, observou-se que o grau de concordância pelo índice Kappa foi classificado como ótimo. Abidu et al. (1996), ao compararem as técnicas de filtro de Visser, quatro tamises e Flukefinder $^{\circledR}$, observaram convergência de resultados e concluíram que elas poderiam ser utilizadas como rotina no diagnóstico da fasciolose. Girão e Ueno (1985) compararam a técnica de quatro tamises com a de Denis et al. (1954) e não observaram diferença quanto ao diagnóstico quantitativo da fasciolose em ruminantes. Apesar dos resultados equivalentes entre as duas técnicas deste estudo, a de quatro tamises parece ser mais apropriada para detecção de ovos de Fasciola hepatica, pois o material necessário para os exames é de fácil obtenção e de baixo custo de confecção e de manutenção dos tamises. Estas observações são semelhantes às de Abidu et al. (1996) e Kleiman et al. (2005), que elegeram a técnica de quatro tamises como a mais fácil de ser utilizada no diagnóstico da fasciolose no campo. Apesar do Flukefinder ${ }^{\circledR}$ ser eficiente, o material para a confecção do aparelho é importado, o que onera o custo operacional. Associado a isto, o tempo de elaboração é maior devido às sucessivas lavagens durante o processamento, além da possibilidade de perder ovos no sobrenadante e de apresentar grande quantidade de sedimento, que dificulta a visualização dos ovos.

$\mathrm{Na}$ escolha da técnica empregada para detecção de ovos de $F$. hepatica a eficiência é fator de extrema importância, devido à necessidade de resultados confiáveis. Entretanto, a operacionalização deve ser levada em consideração, na tentativa de reduzir os custos e o tempo empregado na elaboração dos exames, sem que isto afete a qualidade dos resultados.

Palavras-chave: bovinos, Fasciola hepatica, técnicas coprológicas, diagnóstico

\begin{abstract}
Two different methods to detect Fasciola hepatica in faeces using kappa index were compared with four tamises technics and sequencial fitration in two tamises using Flukefinder ${ }^{\circledR}$ apparatus. High accordance between the two methods was observed. The values showed high sensibility and specificity.
\end{abstract}

Keywords: cattle, Fasciola hepatica, coprological method, diagnosis 


\section{AGRADECIMENTOS}

Ao Professor Ivan Sampaio da Escola de Veterinária - UFMG pelo auxílio na elaboração da análise estatística. À FAPEMIG, ao IMA, à FUNDEP e ao CNPq pelo apoio financeiro. Aos estagiários e técnicos do laboratório de helmintologia do Departamento de Parasitologia do ICB/UFMG pelo auxílio nos procedimentos das análises.

\section{REFERÊNCIAS BIBLIOGRÁFICAS}

ABIDU, M.; SCHERER, P.O.; CARNEIRO, V.S. et al. Estudo comparativo entre técnicas coproparasitológicas para diagnóstico de Fasciola hepatica em bovinos. Rev. Bras. Cienc., v.3 p.1-3, 1996.

ANDERSON, N.; LUONG, T.T.; VON, N.G. The sensitivity and specificity of two methods for detecting Fasciola infections in cattle. Vet. Parasitol., v.83, p.15-24, 1999.

ANDRADE, A.L.S.S.; ZICKER, F. Métodos de investigação epidemiológica em doenças transmissiveis: Brasília: OPAS/FUNASA, 1977. v.1. $182 \mathrm{p}$.

BOVAY, J.C. Flukes of domestic animals. In: GRAAFAR, S.M.; HOWARD, W.E.; MARSH, R.E. (Eds). Parasites pets and predators. Amsterdam: Elsevier, 1985. p.179-218.

CONCEIÇÃO, M.A.P.; DURÃO, R.M.; COSTA, I.H. et al. Evaluation of a simple sedimentation method (modified McMaster) for diagnosis of bovine fasciolosis. Vet. Parasitol., v.105, p.337-343, 2002.

DUMÉNIGO, B.E.; ESPINO, A.M.; FINLAY, C.M. et al. Kinetics of antibody-based antigen detection in serum and faeces of sheep experimentally infected with Fasciola hepatica. Vet. Parasitol., v.89, p.153-161, 2000.

DENNIS, W.R.; STONE, W.M.; SWANSON, L.E. A new laboratory and field doagnostic test for fluke ova in feces. J. Am. Vet. Med. Assoc., v.124, p.47-50, 1954.

GIRÃO, E.S. Técnica de quatro tamises para o diagnóstico coprológico quantitativo da Fasciolose dos ruminantes. 1982. 64f. Dissertação (Mestrado) - Universidade Federal do Rio Grande do Sul, Porto Alegre.

GIRÃO, E.S.; UENO, H. Diagnóstico coprológico quantitativo da fasciolose de ruminantes no Rio Grande do Sul. Pesq. Agrop. Bras., v.20, p.461-466, 1999.

GROCK, R.; MORALES, G.; VACA, J.L. et al. Fasciolosis in sheep in the human high endemic region of the northern Bolivian Altiplano. Res. Rev. Parasitol., v.58, p.95-101, 1998.

KLEIMAN, F.; PIETROKOVSKY, S.; GIL, S. et al. Comparison of two coprological methods for the veterinary diagnosis of fasciolosis. Arq. Bras. Med. Vet. Zootec., v.57, p.181-185, 2005.

SHORE GARCIA, L.; ASH, L.R. Diagnóstico parasitológico 2.ed. Buenos Aires: Panamericana, 1973. 157p.

WATANABE, S.; NAGAYAMA, F.; IWATA, K. Simple detection techinique for Fasciola ova. J. Jpn. Vet. Med. Assoc., v.6, p.176-177, 1953.

OAKLEY, G. A.; OWEN, B.; KNAPP, N. H. Production effects of subclinical liver flukes infection in growing dairy heifers. Vet. Rec., v.104, p.503-507, 1979. 